\title{
Bony Secondaries and Dissemination in Advance Carcinoma Gallbladder: A Longitudinal Study
}

\author{
Amit Nandan DD ${ }^{1 *}$, Alka Singh N², Manoj P², Shukla RC1, and Vijay \\ Kumar $\mathbf{S}^{3}$ \\ 1Department of Radiodiagnosis and Imaging, Banaras Hindu University, India \\ ${ }^{2}$ Department of Surgical Oncology, Banaras Hindu University, India \\ ${ }^{3}$ Department of Surgery, Banaras Hindu University, India
}

\section{Research Article}

Volume 2 Issue 3

Received Date: July 17, 2018

Published Date: August 15, 2018

*Corresponding author: Amit Nandan Dhar Dwivedi, Associate Professor, Department Of Radiodiagnosis and Imaging, Institute of Medical Sciences, Banaras Hindu University, Varanasi, India, Tel: +91-9793856930; Email: amitnandan21@ yahoo.com

\section{Abstract}

Context: Metastasis in carcinoma gall bladder is uncommon and occurs late in the course of the disease. Of all the distant sites that can be involved, the skeletal system is the least common site. We hereby present a prospective longitudinal study depicting the incidence, type, predisposing site and time of presentation of skeletal metastasis in carcinoma gallbladder.

Aims: The present study provides new and important information regarding skeletal metastases which may be more common with the introduction of laparoscopic cholecystectomy and should be excluded before radical resection is contemplated.

Settings and Design: This study was carried from 2010 to 2014. The study was approved by the review board and ethical committee of Institute of Medical Sciences, Banaras Hindu University Varanasi.

Methods and Material: After systemic examination, 95 patients of histopathologically proven and ultrasonographically diagnosed cases of carcinoma gallbladder (GBC) were subjected to contrast enhanced volumetric CT examination of abdomen and pelvis.

Statistical Analysis Used: Data were analyzed using the Statistical Package for Social Sciences (SPSS 16, Chicago, IL, USA).

Results: Four cases were found metastasizing to bones. In case of lumbar vertebral and iliac wing involvement the lesions were hyperdense suggesting osteoblastic metastasis. Osteolytic lesion was noted involving dorsal vertebra. Ala of sacrum showed mixed type of metastasis. All cases were seen in advanced stage of carcinoma. 


\section{Clinical Radiology \& Imaging Journal}

Conclusion: To our knowledge, till date no longitudinal study has been done to assess incidence, type (osteolytic or osteoblastic or mixed), predisposing site and time of presentation (stage) of skeletal metastasis in GBC. The present study provides new and important information regarding the aggressive behaviour of GBC from an endemic geographical zone.

Keywords: Carcinoma Gallbladder (GBC); Skeletal Metastasis; Multidetector Computerized Tomography (MDCT)

Abbreviations: CT: Computed Tomography; DWI: Diffusion Weighted Imaging; DCE: Dynamic Contrast Material Enhanced; PET: Positron Emission Tomography; GBC: Carcinoma Gallbladder.

\section{Introduction}

Carcinoma of the gallbladder (GBC) is the most common malignancy of the biliary tract and the third most common gastrointestinal malignancy in eastern Uttar Pradesh [1]. It is a common disease in countries such as Chile (16-27/100,000), Japan $(7 / 100,000)$, India, Central Europe - Poland (14/100,000), Israel $(5 / 100,000)$ and southern Pakistan $(11 / 100,000)$; however, it is uncommon in the United States $(1.5 / 100,000)$ [2]. In India, GBC is most prevalent in northern and north eastern states of Uttar Pradesh, Bihar, Orissa, West Bengal, Assam [3] and Gangetic delta [4]. GBC is two times higher in women than men and is the leading digestive cancer in women in northern India cities [5] GBC ranks amongst the first 10 cancers in the ICMR registries (2006-2008) of Delhi, Dibrugarh, Kolkata, Bhopal and Mumbai [6]. The incidence of GBC increases after the age of 45 years and found to be highest at the age of 65 years [7]. The incidence rate also varies within the Indian population. It is very high in Northern India, 4.5 per 100,000 for males and 10.1 per 100,000 for females, but low in South India, 1.2 per 100,000 for males and 0.9 per 100,000 for females as reported by the populationbased cancer registry, Delhi [8]. Apart from gallstones, female gender, ethnicity, genetic susceptibility and lifestyle factors are associated risk factors in the development of GBC either as initiators, such as unknown endo- and exobiotic mutagens, or as promoters, including chronic inflammation and infection [9].

\section{The Mode of Spread}

GBC is an aggressive tumour with early dissemination to lymph nodes. The prognosis is poor except when detected incidentally in early stages. It has a five year survival rate of about $5 \%$ with a median survival of about seven months [10].

The surgical management of GBC depends on mode of spread to liver, lymphatic and vascular invasion; direct spread to contiguous organs and intraperitoneal seeding and intraductal i.e. through the cystic duct. Ito and Mishima [11] proposed three pathways of lymphatic drainage from the gallbladder, level I (cholecystoretropancreatic), level II (cholecystoceliac) and level III (cholecystomesenteric). Tsukada, et al. [12] confirmed this theory using the surgical specimens from radical resections. The overall rate of lymph node metastasis in GBC ranges from $54 \%$ to $64 \%$ and is strongly collated with the depth of invasion [13]. Vascular invasion is reported in $15 \%$ of cases [14]. Transperitoneal spread is common and involves liver, common bile duct, colon, duodenum, pancreas, omentum and stomach. Neural spread, which is reported in $25 \%$ to $35 \%$ of cases, is a poor prognostic sign [15]. Skeletal metastasis in gallbladder carcinoma is extremely rare [16]. Only few such case reports are available in English literature showing metastasis to femur, skull or vertebrae [17-20].

\section{Subjects and Methods}

This study was carried from 2010 to 2014 . The study was approved by the review board and ethical committee of Institute of Medical Sciences, Banaras Hindu University Varanasi. The study protocol conformed to the ethical guidelines of the 1975 Declaration of Helsinki (6th revision, 2008). Informed consent was obtained from patients. A total of 95 patients were examined clinically with detailed systemic examination. Stress was made on symptoms and signs like bony pain or pathological fracture. Ultrasound (US) is the primary imaging modality of investigation for screening. USG has high diagnostic accuracy in GBC, but it has limitations in staging of tumour. Philips IU 22 was used for screening all cases. Further, ultrasonographically diagnosed and histopathologically proven cases of GBC were subjected to volumetric CT examination of abdomen and pelvis (plain, post contrast and delayed phase). On clinical suspicion of 


\section{Clinical Radiology \& Imaging Journal}

any extra-abdominal organ involvement additional scan of that particular region were included. Reconstructed images were obtained and detailed assessment of cases was done by experienced radiologists of our department. In case of difference in opinion, common consensus was taken. Data were analyzed using the Statistical Package for Social Sciences (SPSS 16, Chicago, IL, USA).

\section{Results}

In our study of the ninety six cases $(\mathrm{n}=96)$,Based on staging $7 \%$ were T2(n=7), $43.1 \%$ were T3 $(n=T 3), 49.4 \%$ were T4 $(n=47)$, the incidence of bony metastasis was four cases, two cases each in $\mathrm{T} 4$ and $\mathrm{T} 3$ stages respectively Table 1 .

\begin{tabular}{|c|c|c|c|c|c|c|}
\hline \multirow{2}{*}{ Stage } & \multirow{2}{*}{ No. of Cases } & \multirow{2}{*}{$\%$} & \multicolumn{3}{|c|}{ Skeletal Metastasis } & \multirow{2}{*}{ Sites of Skeletal Metastasis } \\
\hline & & & Osteoblastic & Osteolytic & Mixed & \\
\hline $\mathrm{T}$ is & - & - & & & & \\
\hline T1 & - & - & & & & \\
\hline $\mathrm{T} 2$ & 7 & 7.3 & & & & \\
\hline T3 & 41 & 43.1 & 2 & & & Vertebra, Iliac wing \\
\hline $\mathrm{T} 4$ & 47 & 49.4 & & 1 & 1 & Vertebra, Ala of sacrum \\
\hline
\end{tabular}

Table 1: T Staging with Site Predilection and Incidence of Bony Metastasis in Carcinoma Gallbladder.

Based on the incidence of loco-regional and distal spread of carcinoma gallbladder, hepatic invasion was the most common constituting $77.8 \%$, followed by lymph nodal metastasis (61\%), hepatic metastasis (43.1\%), porta invasion (40\%), mass replacing GB fossa (40\%) and the incidence of bony metastasis constituted $4.7 \%(n=4)$, Table 2 .

\begin{tabular}{|c|c|c|}
\hline MDCT Observations & Number of Cases & Percentage \\
\hline Irregular Diffuse GB Wall Thickening & 7 & $7.3 \%$ \\
\hline Mass Replacing GB Fossa & 38 & $40 \%$ \\
\hline Focal Mass Lesion & 20 & $21 \%$ \\
\hline Hepatic Invasion & 74 & $77.8 \%$ \\
\hline Porta Invasion & 38 & $40 \%$ \\
\hline CBD Invasion & 24 & $25.2 \%$ \\
\hline D1 and D2 Part of Duodenum Invasion & 36 & $37.9 \%$ \\
\hline Hepatic Flexure Invasion & 26 & $27.3 \%$ \\
\hline Portal Vein Invasion & 9 & $9.4 \%$ \\
\hline Hepatic Metastasis & 41 & $43.1 \%$ \\
\hline Lymphnodal Metastasis & 58 & $61 \%$ \\
\hline Peritoneal Deposits & 18 & $18.9 \%$ \\
\hline Lung Metastasis & 6 & $6.3 \%$ \\
\hline
\end{tabular}

Table 2: Incidence of Loco-Regional and Distant Spread of Carcinoma Gallbladder.

In case of lumbar vertebral and iliac wing involvement the lesions were hyper dense suggesting osteoblastic metastasis (Figure 1). In second case hypodense lesions was noted involving dorsal vertebra which suggest osteolytic metastasis (Figure 2). Ala of sacrum showed both osteolytic and osteoblastic type of metastasis (Figure 3 ). All 4 cases involved axial skeleton. All cases were seen in advanced stage of carcinoma (T3 and T4). Among patients of Gall bladder carcinoma with skeletal secondaries, two presented clinically with features related to secondaries, while the other two had advanced metastatic disease presenting with obstructive jaundice (Table 3). 


\section{Clinical Radiology \& Imaging Journal}

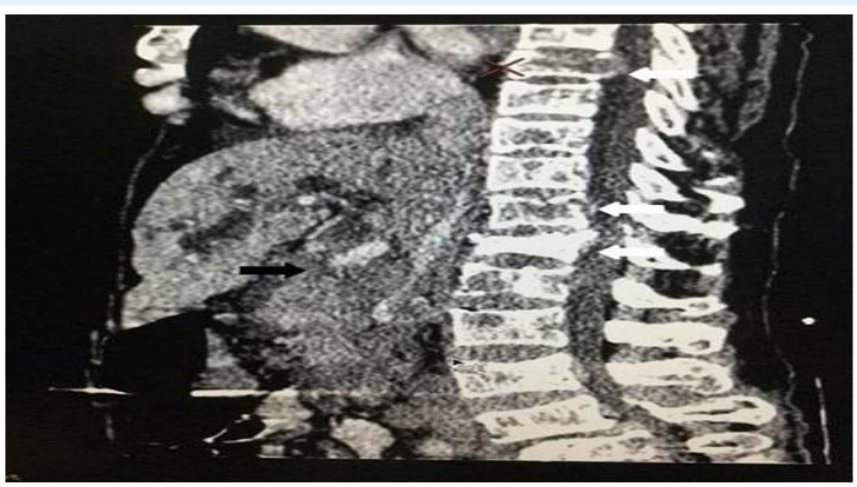

Figure 1: Sagittal section of contrast enhanced MDCT shows carcinoma gallbladder (black arrow) with mixed osteoblastic and lytic skeletal metastasis (white arrow).

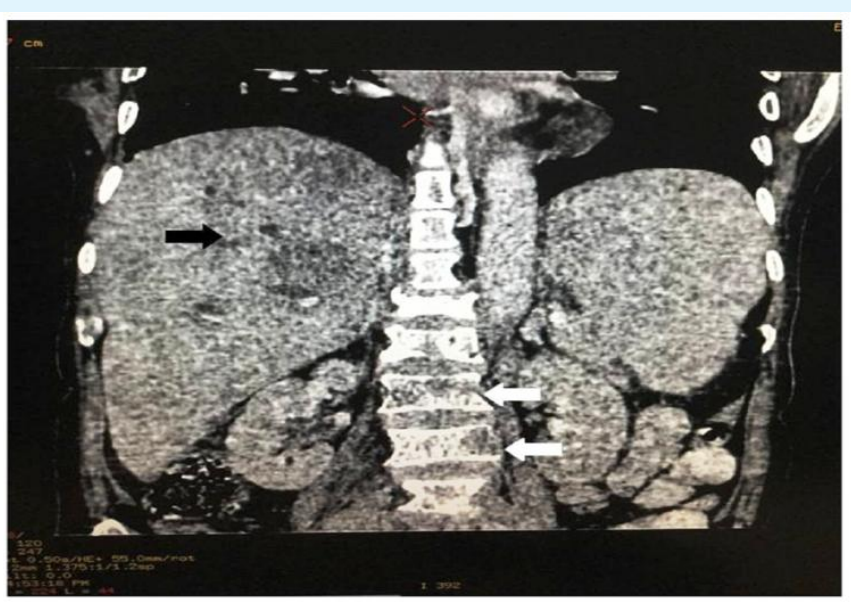

Figure 2: Contrast enhanced MDCT coronal section of carcinoma gallbladder (black arrow) presenting with multiple osteolytic vertebral metastases (white arrow).

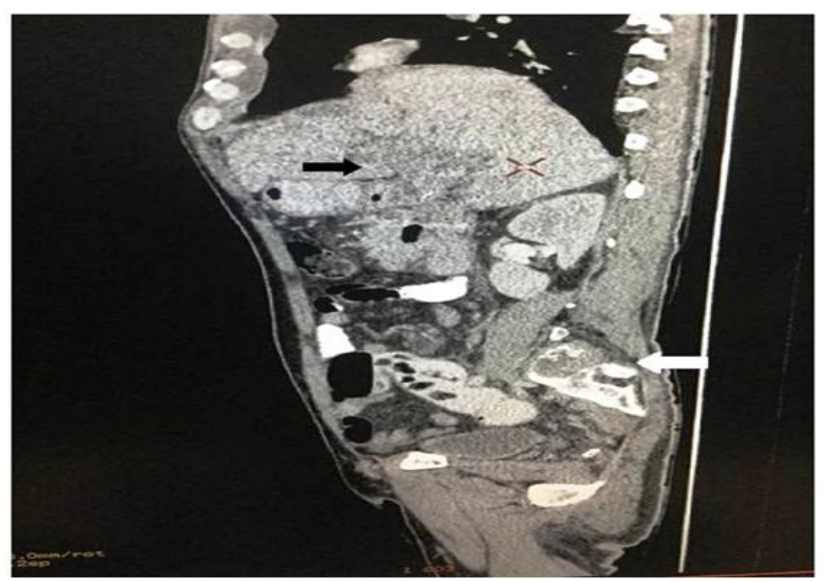

Figure 3: Sagittal section of contrast enhanced MDCT of a large mass replacing gallbladder fossa (black arrow) with sacral vertebral metastasis (white arrow). 


\section{Clinical Radiology \& Imaging Journal}

\begin{tabular}{|c|c|c|c|c|c|c|}
\hline Metastasis & Type & Type of Primary & Locoregional Spread & $\begin{array}{c}\text { Other Metastatic } \\
\text { lesions }\end{array}$ & $\begin{array}{c}\text { Clinical } \\
\text { presentation }\end{array}$ \\
\hline Case 1 & $\begin{array}{c}\text { L4 vertebra } \\
\text { and Right iliac } \\
\text { wing }\end{array}$ & $\begin{array}{c}\text { Sclerotic } \\
\text { metastasis }\end{array}$ & Mass in GB fossa & $\begin{array}{c}\text { Liver infiltration, porta and } \\
\text { CBD invasion }\end{array}$ & $\begin{array}{c}\text { Hepatic and lymph } \\
\text { nodal metastasis }\end{array}$ & $\begin{array}{c}\text { Obstructive } \\
\text { jaundice }\end{array}$ \\
\hline Case 2 & $\begin{array}{c}\text { D5 vertebral } \\
\text { body and } \\
\text { right pedicle }\end{array}$ & $\begin{array}{c}\text { Lytic } \\
\text { metastasis }\end{array}$ & $\begin{array}{c}\text { Mass replacing GB } \\
\text { fossa }\end{array}$ & $\begin{array}{c}\text { Liver infiltration, porta, CBD, } \\
\text { duodenal and hepatic } \\
\text { flexure invasion }\end{array}$ & $\begin{array}{c}\text { Hepatic and } \\
\text { pulmonary } \\
\text { Metastasis }\end{array}$ & $\begin{array}{c}\text { Obstructive } \\
\text { jaundice }\end{array}$ \\
\hline Case 4 & $\begin{array}{c}\text { L3 and sacral } \\
\text { vertebrae }\end{array}$ & $\begin{array}{c}\text { Mixed lytic } \\
\text { and } \\
\text { sclerotic } \\
\text { metastasis }\end{array}$ & $\begin{array}{c}\text { GB asymmetrical } \\
\text { wall thickening }\end{array}$ & Infiltration into liver & None & Back pain \\
Periportal lymph nodes & Back pain \\
\hline
\end{tabular}

Table 3: CT scan Findings in Cases of Gall Bladder Carcinoma with Skeletal Metastasis.

\section{Discussion}

Carcinoma gallbladder (GBC) is a lethal malignancy with marked ethnic and geographical variations. The presenting symptoms are vague so that its diagnosis occurs at an advanced stage. The overall 5-year survival of patients remains low. Carcinoma gall bladder mostly presents in advanced stage with abdominal symptoms and obstructive jaundice. In presence of metastasis, the management is palliative and role of chemotherapy is limited for palliation of symptoms. There is a clear worldwide association between chronic cholelithiasis and GBC $[9,21]$. Aside from gallstones, female gender, ethnicity, genetic susceptibility and lifestyle factors a number of associated risk factors appear to favour the development of Ca GB $[9,22]$. A CT scan is used for assessing gallbladder mass, wall thickening, polyp and tumour staging. CT reveals depth of infiltration into the liver and extension into stomach, duodenum, colon or pancreas [23]. Ancillary findings on CT include gall stones, wall calcification, and dilated biliary radicals. When vascular invasion occurs, it leads to localized involvement of the liver in the neighbourhood of the primary lesion rather than disseminated multiple nodules [24]. Disseminated metastases occur late in the course of the disease and are probably due to invasion of the retroperitoneal veins. CT also helps to assess peritoneal deposits, hepatic metastasis and lymphatic dissemination thereby helping in staging the disease more accurately $[23,24]$. High positive predictive value of CT means that it is useful for determining resectability and assisting treatment planning [25]. Infiltrated lymph nodes are > $1 \mathrm{~cm}$, ring shaped with heterogeneous uptake after contrast administration [26]. Pericholedochal nodes are most frequently involved followed by cystic nodes [12]. The sensitivity of CT is 0.36 to 0.47 for $\mathrm{N}$-staging (PPV: 0.94; NPV: 0.92); 0.65 for hepatic infiltration of $<2 \mathrm{~cm}$
(PPV: 0.77) and 1.0 for $>2 \mathrm{~cm}$ (PPV: 1.0); 0.50 for spread to extrahepatic bile duct (PPV: 0.90), 0.57 for gastrointestinal or pancreas (PPV: 0) and 0.71 for detection of hepatic metastases (PPV: 1.0) [27]. Koo, et al. [28] found bone metastases in only 2 out of 100 cases of metastatic carcinoma of the gall bladder studied by them. The incidence of bone metastasis in carcinoma gall bladder is very low and, when present, it is usually associated with advanced disease. Hence, a bone scan is not included in the routine work-up of gall bladder cancer patients.

In our study, the stage distribution according to the TNM system revealed $n=0$ patients at stages $I, n=7$ in stage II, $n=41$ in stage III and $n=47$ in stage IV. Among these, 4 cases were found metastasizing to bones i.e. Dorsal and lumbar vertebrae, ala of sacrum and iliac wing was involved. All These cases were seen in advanced stage of carcinoma (T3 \& T4). Preoperative staging using helical CT has an overall accuracy ranging from 83 to $86 \%$ [2729]. Most of the time the disease is diagnosed in advanced stage, making the prognosis poor. The overall prognosis was significantly determined by metastatic spread to the lymph nodes [30]. The present study shows that the incidence of skeletal metastasis in cases of Gall bladder carcinoma might be under-reported in the literature. Moreover, two patients in the present study presented with complaints pertaining to the bony metastasis with clinically silent Gall bladder disease. To the best of our knowledge, less than 10 cases have been reported in literature with gall bladder malignancy, clinically presenting with clinical features of skeletal secondaries. The reported sites of skeletal secondaries were femur, clavicle, humerus, calvaria, and lumbar vertebrae [31-34]. The recognition of skeletal metastasis is clinically important to tailor the appropriate palliative care, even when the bony disease is clinically silent. This study was 


\section{Clinical Radiology \& Imaging Journal}

performed with a 64-row CT scanner, which was associated with radiation exposure. Positron emission tomography is a sensitive imaging modality for detection of metastases, but it is also associated with radiation exposure like computerised tomography and is expensive [35]. Recent developments and new clinical applications of conventional imaging techniques (eg, dual-energy spectral computed tomography [CT], elastography, and virtual colonoscopy) may offer additional information in patients undergoing metastatic work up. Moreover, imaging findings derived from functional and molecular imaging with diffusion-weighted imaging (DWI), dynamic contrast material-enhanced (DCE) imaging, blood oxygen level-dependent imaging, positron emission tomography (PET) with different radiotracers, and MR spectroscopy may be critical in decision making for patients with secondaries [36].

Bone scan was not performed to provide a complete skeletal survey in any of the patients which can be attributed to the retrospective nature of this study. The authors' conclude that addition of bone scans to imaging protocol of these patients would further add up to the total number of cases with skeletal secondaries. The overall implication of the presence of bony metastasis on the patient's survival could not be ascertained as most of the patients were lost in follow up.

\section{Conclusion}

The presence of undiagnosed systemic and bony metastases from gallbladder cancer might explain its poor prognosis despite radical surgery. To our knowledge, till date no longitudinal study has been done to assess incidence, type (osteolytic or osteoblastic or mixed), predisposing site and time of presentation (stage) of skeletal metastasis in GBC. The present study provides new and important information regarding skeletal metastases which may be more common with the introduction of laparoscopic cholecystectomy and should be excluded before radical resection is contemplated. We further emphasize that skeletal metastasis might be more common than presently reported and an addition of skeletal survey in diagnostic algorithm will help in guiding the palliative therapy.

\section{References}

1. Shukla VK, Khandelwal C, Roy SK, Vaidya MP (1985) Primary carcinoma of gall bladder: A review of a 16year period at the university hospital. J Surg Oncol 28(1): 32-35.
2. Consensus document for management of GALLBLADDER CANCER (2014). Indian Council of Medical Research.

3. Nandakumar A, Gupta PC, Gangadharn P, Visweswara RN, Parkin DM (2005) Geographic pathology revisited: development of an atlas of cancer in India. Int J Cancer 116(5): 740-754.

4. Kaushik SP, Kapoor VK, Haribhakti SP (1997) Carcinoma gallbladder. GI Surg Annual 4: 87-101.

5. Dhir V, Mohandas KM (1999) Epidemiology of digestive tract cancers in India IV. Gall bladder and pancreas. Indian J Gastroenterol 18(1): 24-28.

6. National Cancer Registry Programme. Three-Year report of the Population Based Cancer Registries 2006-2008. New Delhi: Indian Council of Medical Research 2010.

7. Murthy NS, Rajaram D, Gautham MS, NS Shivraj, Sreekantaiah P, et al. (2011) Trends in incidence of gallbladder cancer-Indian scenario. In: Gastrointestinal cancer: Targets and therapy 1: 1-9.

8. Indian council of medical Research (ICMR) (1993) Annual report of population based cancer registries of the National Cancer Registry programme. New Delhi: ICMR publication 18.

9. Chaurasia P, Thakur MK, Shukla HS (1999) What causes cancer gallbladder? A review. HPB Surg 11(4): 217-224.

10. Grobmyer SR, Lieberman MD, Daly JM (2004) Gallbladder cancer in the twentieth century: Single institution's experience. World J Surg 28(1): 47-49.

11. Ito M, Mishima Y, Sato T (1991) An anatomical study of the lymphatic drainage of the gallbladder. Surg Radiol Anot 13(2): 89-104.

12. Tsukada K, Kurosaki I, Uchida K, Shirai Y, Oohashi Y, et al. (1997) Lymph node spread from carcinoma of the gallbladder. Cancer 80(4): 661-667.

13. Muratore A, Polastri R, Capussotti L (2000) Radical surgery for gallbladder cancer: current options. Eur J Surg Oncol 26(5): 438-443.

14. Misra MC, Guleria S (2006) Management of cancer gallbladder found as a surprise on a resected gallbladder specimen. J Surg Oncol 93(8): 690-698. 


\section{Clinical Radiology \& Imaging Journal}

15. Fahim RB, McDonald JR, Richards JC, Deward OF (1962) Carcinoma of the Gallbladder: a study of its models of spread. Ann Surg 156(1): 114-124.

16. Prakash M, Senthil KA, Kumar A, Radhika S, Yadav TD, et al. (2010) Solitary skeletal metastasis in carcinoma gallbladder: two case reports. Cancer Imaging 10(1): 121-123.

17. Kumar A, Bhargava SK, Upreti L, Kumar J (2003) Disseminated osteoblastic skeletal metastasis from carcinoma gall bladder- a case report. Indian J Radiol Imaging 13(1): 37-39.

18. Singh S, Bhojwani R, Singh S, Bhatnagar A, Saran RK (2007) Skeletal metastasis in gall bladder cancer. HPB (Oxford) 9(1): 71-72.

19. Misra S, Chaturvedi A, Misra NC (1997) Carcinoma gallbladder presenting with skeletal metastases. Indian J Gastroenterol 16: 74.

20. Kohli A, Chib RS, Parihar BK (1994) Secondary Involvement of Femur in Carcinoma of Gall Bladder. Indian J Cancer 31(4): 257-259.

21. Kapoor VK, Mc Michael AJ (2003) Gall Bladder Cancer: An Indian disease. Nat Med J India 16(4): 209-213.

22. Strom BL, Soloway RD, Rioz-Palenz JL, RodriguezMartinez HA, West SL, et al. (1995) Risk factors for gallbladder cancer. An international collaborative case-control study. Cancer 76(10): 1747-1756.

23. Amit ND, Manoj P, Shukla RC, Shukla VK, Gaharwar S, et al. (2012) Biological behavior and disease pattern of carcinoma gall bladder shown on 64 slice CT scanner: A hospital based retrospective observational study and our experience. Indian J Cancer 49(3): 303308.

24. Dwivedi AN, Jain S, Dixit R (2015) Gall bladder carcinoma: Aggressive malignancy with protean locoregional and distant spread. World J Clin Cases 3(3): 231-244.

25. Ohtani T, Shirai Y, Tsukada K, Muto T, Hatakeyama K, et al. (1996) Spread of gallbladder carcinoma: CT evaluation with pathologic correlation. Abdom Imaging 21(2): 195-201.

26. Efremidis SC, Vougiouklis N, Zafiriadou E, Sofianou F, Sbarounis C, et al. (1999) Pathways of lymph node involvement in upper abdominal malignancies: Evaluation with high- resolution CT. Eur Radiol 9(5): 868-874.

27. Yoshimitsu K, Honda H, Shinozaki K, Aibe H, Kuroiwa T, et al. (2002) Helical CT of the local spread of carcinoma of the gall bladder: Evaluation of the gall bladder: Evaluation according to the TNM system in patients who underwent surgical resection. AJR Am J Roentgenol 179(2): 423-428.

28. Koo J, Wong J, Cheng FCY, Ong GB (1981) Carcinoma of the gall bladder. Br J Surg 68(3): 161-165.

29. Grand D, Horton MK, Fishman EK (2004) CT of the gall bladder: Spectrum of disease. AJR 183(1): 163170.

30. Rückert JC, Rückert RI, Gellert K, Hecker K, Müller JM (1996) Surgery for carcinoma of the gallbladder. Hepatogastroenterology 43(9): 527-533.

31. Jain G, Samaiya A, Mohindra N, Patel K (2009) Bone metastasis as the initial presentation of carcinoma of gall bladder: A rarity. Indian J Surg 71(1): 35-37.

32. Joshi MK, Joshi R, Chadha M, Alam SE, Varshneya H, et al. (2013) Gall Bladder Carcinoma Presenting with Spinal Metastasis: A Rare Phenomenon Indian J Palliat Care 19(2): 113-115.

33. Pandey M, Aryya NC, Pradhan S, Asthana AK, Gautam A, (1998) Carcinoma of the gallbladder presenting as scalp tumour. Eur J Surg Oncol 24(6): 605-607.

34. Singh A, Singh OP, Goel MM (2005) Frozen shoulder as the initial presentation of gall bladder cancer diagnosed by fine needle aspiration cytology. Acta Cytol 49(3): 345-347.

35. Ghobrial FEI, Eldin MS, Razek AAKA, Atwan NI, Shamaa SSA (2017) Computed Tomography Assessment of Hepatic Metastases of Breast Cancer with Revised Response Evaluation Criteria in Solid Tumors (RECIST) Criteria (Version 1.1): InterObserver Agreement. Pol J Radiol 82: 593-597.

36. García-Figueiras R, Baleato-González S, Padhani AR, Luna-Alcalá A, Marhuenda A, et al. (2018) Advanced Imaging Techniques in Evaluation of Colorectal Cancer. Radiographics 38(3): 740-765. 